Research Article

\title{
Investigation of Flexural Fatigue Behavior of Concrete Beams Reinforced with Intelligent CFRP-OFBG Plates
}

\author{
Langni Deng $(\mathbb{D}$, Yang Liu $(\mathbb{D}$, Ling Liao, Hong Xie, Xiaoxia Huang, Shijin Lai $(\mathbb{D}$, \\ and Mengjun Zhong $\mathbb{D}$ \\ School of Civil Engineering and Architecture, Guangxi University of Science and Technology, Liuzhou 545006, China \\ Correspondence should be addressed to Langni Deng; langni666@126.com
}

Received 12 October 2019; Revised 31 January 2020; Accepted 8 February 2020; Published 31 March 2020

Academic Editor: Daniele Baraldi

Copyright ( 2020 Langni Deng et al. This is an open access article distributed under the Creative Commons Attribution License, which permits unrestricted use, distribution, and reproduction in any medium, provided the original work is properly cited.

\begin{abstract}
The fatigue properties of concrete beams reinforced with carbon fiber-reinforced polymer-optical fiber Bragg grating (CFRPOFBG) plates under three-point bending constant cyclic loading were experimentally studied. According to the experimental findings, the mechanism of fatigue failure in reinforced beams was presented, and the corresponding empirical equations were established for the prediction of the fatigue lives of these components. Besides, based on the real-time monitoring data of the intelligent CFRP-OFBG plates, a fatigue accumulative damage model was established using flexural bending stiffness for the prediction of fatigue life. Through example verification, it was found that the fatigue life predicted by the model had less error and was safer than the fatigue failure cycle number of the reinforced beam obtained by experimental tests.
\end{abstract}

\section{Introduction}

In recent years, fiber-reinforced polymers (FRP) have been widely used for reinforcing concrete structures. These structures have advantages such as elimination of the need for heavy equipment, ease of handing and application, high strength, higher construction speed, lightweight, and lack of corrosion [1-3]. Therefore, compared with traditional reinforcement methods [4], the developed reinforcement technology has obvious advantages in construction methods, construction treatments, shortening construction periods, and so on, so that it has attracted the attention of researchers working on reinforced concrete beams or actual bridge reinforcement engineering.

Many factors, such as bridge structure, mechanical properties of original concrete, and environmental conditions, change after strengthening reinforced concrete bridge. Insisting on the application of the original method to assess the service life of bridges after reinforcement is not reasonable. The methods currently used for predicting the fatigue life of in-service bridges are generally based on fracture mechanics, strain, stress, damage variables, and energy method. Many researchers have done some work in this area [5-13]. In these studies, some have proposed and continuously improved the application of crack propagation equations in fatigue life prediction based on fracture mechanics [5-8]. Other studies focus on reliability calculation method of structural fatigue bearing capacity and have proposed an existing method for predicting fatigue remaining life of existing bridge structures based on reliability theory $[9,10]$. A preliminary study was performed on fatigue life estimation of CFRP-reinforced steel structures using fracture mechanics combined with health monitoring technology [11].

CFPR sheets are commonly used in bridge reinforcement, if we can give long-term monitoring performance to the reinforcement material, so that it can reflect structural bearing capacity during service and be used in more accurate assessment of fatigue life. That is of a great significance to the remaining service life prediction and maintenance optimization decision of the service bridge structure.

However, not many research works have been conducted on the development and application of new building materials for structural health monitoring based on strain and stress sensing [14-17]. The obtained results have shown that the developed materials met the needs of structural health 
monitoring. In recent years, Deng et al. have performed extensive experimental research on the development of new intelligent materials for structural health monitoring [18-21]. CFRP-OFBG plates with self-monitoring performance were developed based on fiber-reinforced composite materials and optical fiber Bragg grating (OFBG) sensing technology $[19,20]$. This laid a good foundation for the performance monitoring and investigation on the fatigue behaviors of reinforced concrete beams.

Therefore, in this study, taking intelligent CFRP-OFBG plate reinforced concrete beams as research object, a threepoint bending fatigue cyclic load test under constant cyclic load amplitude was performed and stable long-term monitoring data of intelligent CFRP-OFBG plate were used to evaluate fatigue performance and predict the remaining life of the reinforced beam under fatigue conditions.

\section{Experimental Program}

In this section, major features of test samples, their materials properties, experimental loading device, data acquisition systems, and other equipment are described.

2.1. Specimens' Details. In all, seven rectangular-section specimens were tested in the current work of which five were reinforced and two were unreinforced beams all with a length of $1800 \mathrm{~mm}$, cross-section dimensions of $120 \mathrm{~mm} \times 200 \mathrm{~mm}$, and calculated span of $1600 \mathrm{~mm}$. Figure 1 presents the typical reinforcement and geometry of test specimens. Concrete strength was designed to be C30 with elastic modulus and cube compressive strength of $33.0 \mathrm{GPa}$ and $41.38 \mathrm{MPa}$, respectively. Elastic modulus and yield strength of main tensile steel bars were $200 \mathrm{GPa}$ and 608.40 MPa, respectively.

Beams were externally reinforced with CFRP-OFBG plates which were knitted through pultrusion process with CFRP silks as reinforcing material and vinyl resin, and the OFBG was used as intelligent monitoring material [20]. The elastic modulus and ultimate tensile strength of CFRP plate was $160 \mathrm{GPa}$ and $2600 \mathrm{MPa}$, respectively. The width and nominal thickness of CFRP-OFBG plate were $30 \mathrm{~mm}$ and $1.5 \mathrm{~mm}$, respectively.

The reinforcement method was the bottom outer sticker, and the two ends were entangled with a carbon fiber fabric to form an annular hoop reinforcement. To improve the quality of bonding among CFRP-OFBG plate, carbon fiber fabric, and concrete, a fix pressure was applied by a pressing device for a natural conservation period of seven days. A total of five reinforcing beams, labelled as JB-2, JB-3, JB-4, JB-5, and JB-6, were created. Figure 2 shows the schematic diagram of reinforcing beam.

2.2. Testing Procedure. Three-point bending was applied to all beam specimens. Static tests were performed on reinforced specimen JB-2 and unreinforced specimen B-1 to obtain the static carrying capacity of specimens. Fatigue tests were performed on an MTS-650 electrohydraulic servo fatigue tester, as shown in Figure 3. Loading frequency of $5 \mathrm{~Hz}$ different fatigue loads were applied by a force-controlled equal-amplitude sinusoidal waveform with a stress ratio of 0.2 .

Before fatigue tests, static loads of up to a low value were applied to specimens for 5 minutes to eliminate the gaps between the various parts of loading system, checkout loading system, and data acquisition systems which were verified. During fatigue tests, specimens were subjected to low-cycle repeated fatigue loads and strain values were measured by a JM3841 dynamic static strain collector. Date acquisition frequency was adjusted at $50 \mathrm{~Hz}$ to obtain higher date volume. FBG sensor was connected to GM8050 C distributed fiber grating demodulator, which was responsible for real-time monitoring of fatigue stress on CFRP plates during the test.

\section{Results and Discussion}

Experimental findings, including stress level, load-carrying capacity, failure modes, and fatigue lives of specimens, are presented in Table 1.

3.1. Static Test. As can be seen in Figure 4, CFRP-OFBG debonding following tensile steel yield was the main specimen failure mode in static tests. Load versus the midspan deflection diagrams of B-1 and JB-2 specimens are presented in Figure 4.

As shown in the curve, the bearing capacities of reinforced beams were significantly greater than those of the unreinforced beams. The entire loading process was classified into three phases: (1) elastic phase, where load-midspan deflection relationship was linear; (2) yielding phase, where deflection was rapidly increased compared to previous phase and the same relationship was approximately linear, but curve slope was lower than the first phase; and (3) failure phase, in which curves were irregular.

\subsection{Fatigue Test}

3.2.1. Fatigue Failure Process. Fatigue failures of all test beams were due to the fracturing of midspan tensile reinforcement followed by CFRP-OFBG debonding. Fatigue failures of reinforced beams were divided into the following three stages [22]:

(1) Crack initiation stage in which concrete stress near CFRP-OFBG reached its tensile strength and curved cracks were created. Then, one of the cracks rapidly expanded and formed the main crack. The creation and propagation of the main crack led to the concentration of stress at crack roots of CFRP-OFBGconcrete interface, which eventually resulted in interface weakening or partial debonding. Although the process at this stage was about $2-5 \%$ of the fatigue life, beam stiffness was rapidly degraded.

(2) Stable expanding stage where, after the first phase, fatigue crack expansion was stabilized and new bending cracks appeared far in the midspan. This 


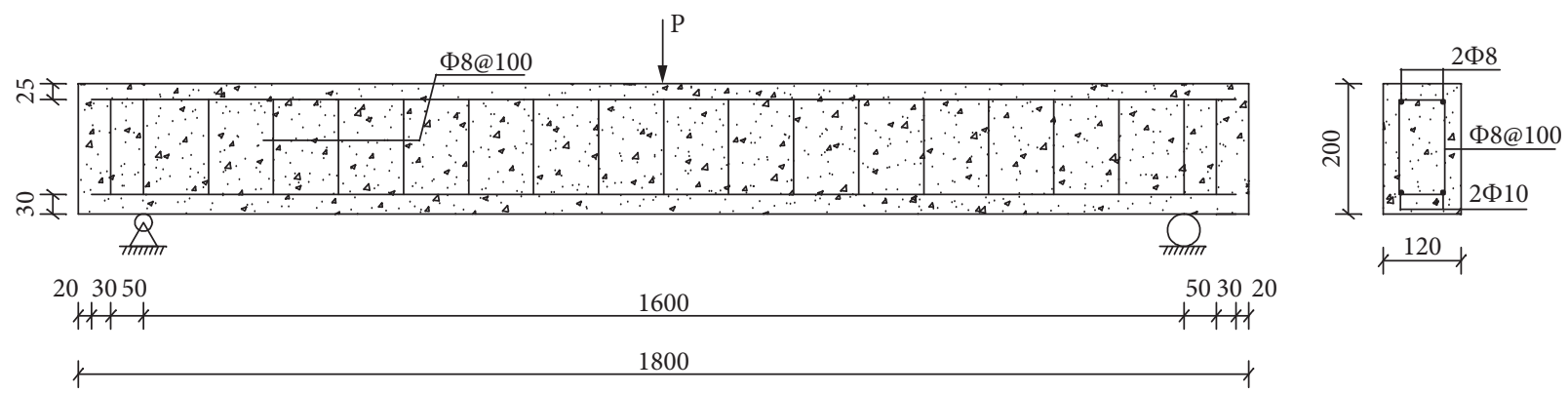

Figure 1: Test beam design and loading scheme.

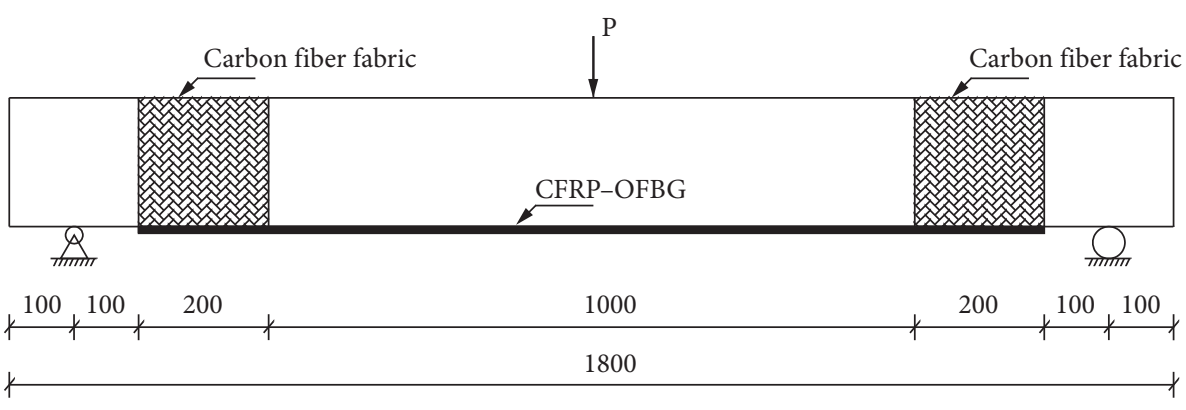

(a)

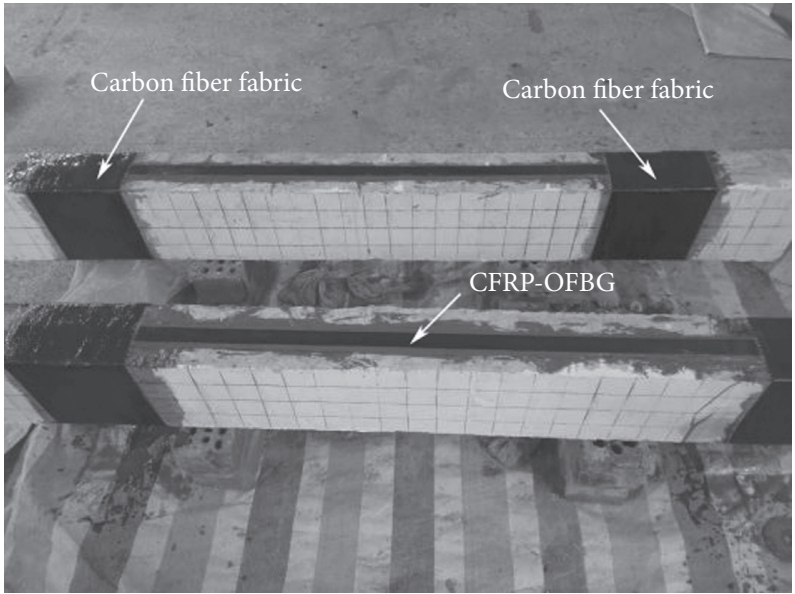

(b)

Figure 2: CFRP-OFBG plate reinforced concrete beam diagram.

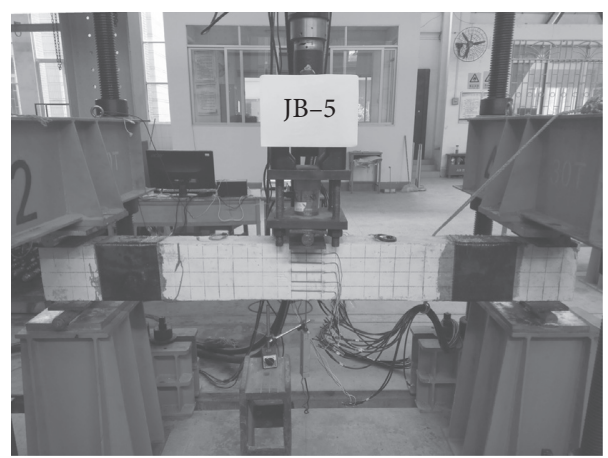

Figure 3: Loading test device on-site. 
TABLE 1: Experimental loading conditions and results.

\begin{tabular}{|c|c|c|c|c|c|c|c|c|c|}
\hline Specimen & $\begin{array}{c}\text { Carrying } \\
\text { capacity }(\mathrm{kN})\end{array}$ & $\begin{array}{l}\text { Load } \\
\text { limit } \\
(\mathrm{kN})\end{array}$ & $\begin{array}{l}\text { Stress } \\
\text { ratio } R^{a}\end{array}$ & $\begin{array}{l}\text { Frequency } \\
\qquad(\mathrm{Hz})\end{array}$ & $\begin{array}{l}\text { Stress level } \\
P_{\max }^{f} / P_{u}\end{array}$ & $\begin{array}{l}\text { Fatigue } \\
\text { life } N_{G}^{b}\end{array}$ & $\begin{array}{l}\text { Fatigue } \\
\text { life } N_{f}^{c}\end{array}$ & Failure mode & Note \\
\hline B-1 & 43.0 & - & - & - & - & 1 & 1 & $\begin{array}{l}\text { Steel yield and the } \\
\text { concrete was crushed }\end{array}$ & Static \\
\hline JB-2 & 53.0 & - & - & - & - & $1 \mathrm{~N}$ & 1 & $\begin{array}{c}\text { and concrete was } \\
\text { crushed }\end{array}$ & test \\
\hline B-3 & - & $5.4 \sim 27$ & & & 0.628 & 9.40 & - & Steel fracture & \\
\hline $\mathrm{JB}-3$ & - & $5.4 \sim 27$ & & & 0.509 & 109.48 & 114.52 & $\begin{array}{l}\text { Steel fracture followed } \\
\text { by debonding }\end{array}$ & \\
\hline JB-6 & - & $6.0 \sim 30$ & 0.2 & 5 & 0.566 & 63.98 & 66.44 & $\begin{array}{l}\text { Steel fracture followed } \\
\text { by debonding }\end{array}$ & Fatigue \\
\hline JB-4 & - & $6.6 \sim 33$ & & & 0.623 & 37.67 & 37.67 & $\begin{array}{l}\text { Steel fracture followed } \\
\text { by debonding }\end{array}$ & \\
\hline JB-5 & - & $7.8 \sim 39$ & & & 0.736 & 8.96 & 8.96 & $\begin{array}{l}\text { Steel fracture followed } \\
\text { by debonding }\end{array}$ & \\
\hline
\end{tabular}

${ }^{\mathrm{a}} R=P_{\min } / P_{\max }, P_{\min }$ is lower load. ${ }^{\mathrm{b}} N_{G}\left(10,000\right.$ cycles) is fatigue lives of corresponding components when steel bar was fatigue fractured. ${ }^{\mathrm{c}} N_{f}(10,000$ cycles $):$ the carbon plate is completely peeled off and test pieces completely damaged to corresponding fatigue lives.

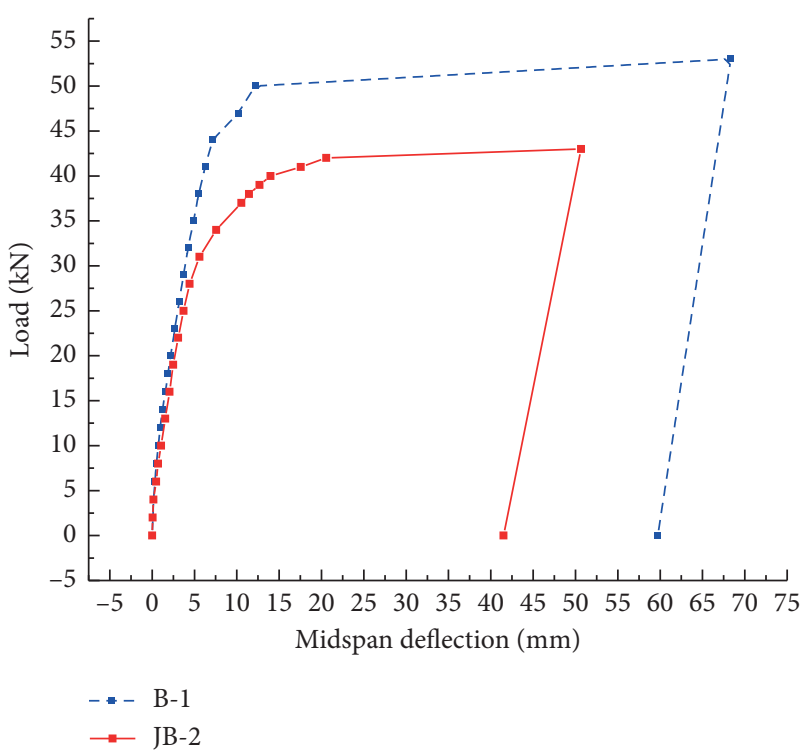

FIGURE 4: Load versus midspan deflection curves under monotonic loads.

stage consisted about $85-90 \%$ of fatigue life and little changes in beam deformation were observed.

(3) Rapidly expanding failure stage in which, by the increase of load cycle, tensile reinforcement was first fractured because of fatigue damage accumulation. Then, the redistribution of cross-sectional stress suddenly increased CFRP-OFBG stress. Therefore, interface crack propagation was unstable, resulting in rapid final debonding of CFRP-OFBG from midspan. Almost at the same time, because of concrete crushing in compression zone, concrete in nip was rapidly reduced and resulted in load-carrying capacity of reinforced beams being suddenly lost. The final beam failure forms included debonding, steel fracturing, and concrete crushing in compression zone as shown in Figure 5.

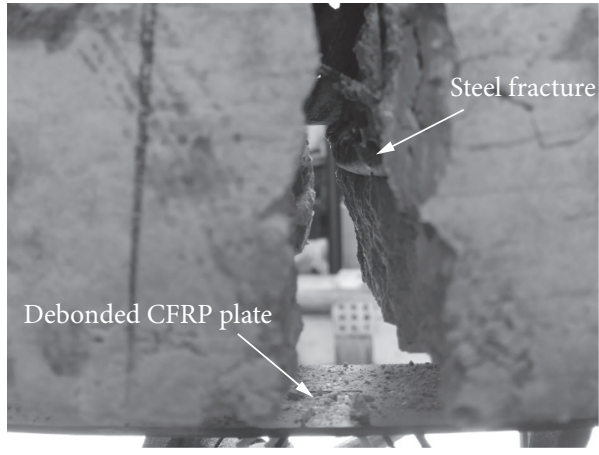

Figure 5: Typical failure of fatigue specimens.

3.2.2. Deflection Evolvement. Figure 6 shows load-mid-span deflection relationship of reinforced beams with no damage. As can be seen in Figure 6(a), the unreinforced test specimen B-3 was tested under the upper load of $27 \mathrm{kN}$. Comparing Figure 6(a) with Figure 6(b) showed that the residual deflection of reinforced specimen JB-3 after one million cycles was much smaller than that of reinforced specimen B-3 after 50,000 cycles, which was a good illustration of the effectiveness of CFRP-OFBG reinforcement in improving components. Overall stiffness allowed better crack control, and therefore, lower deflections at the same load were witnessed in specimen JB-3.

Specimen midspan deflections from the first cycle to the failed upper load are shown in Figure 7. It was seen in the figure that midspan deflection change followed a three-stage evolution pattern (same as strain development in steel and concrete). Due to crack formation, the deflection of reinforced beams was rapidly increased during early cycles. Then, before impending failure, deflection increase rate was significantly slowed down due to internal damage accumulation in concrete beams under cyclic loading. In case of failure, deflection curve developed very rapidly due to the sudden breakage of tensile reinforcement and reduction of component stiffness. 


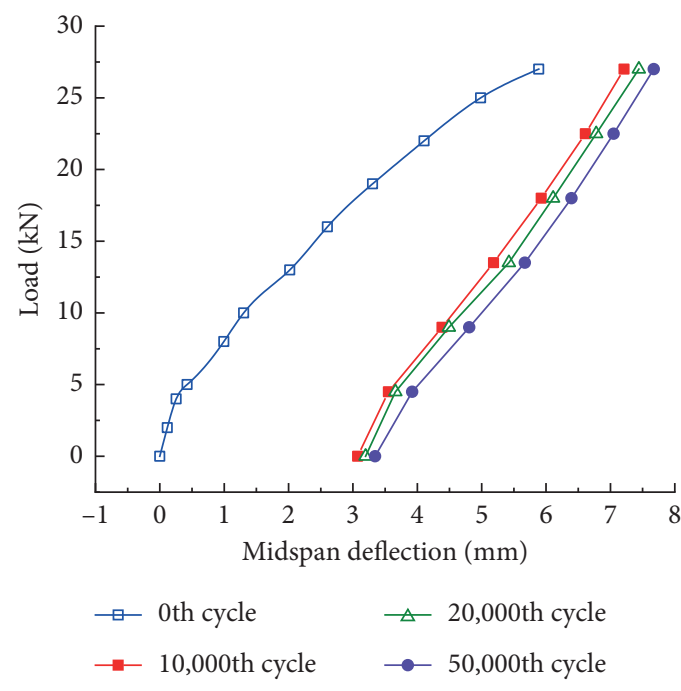

(a)

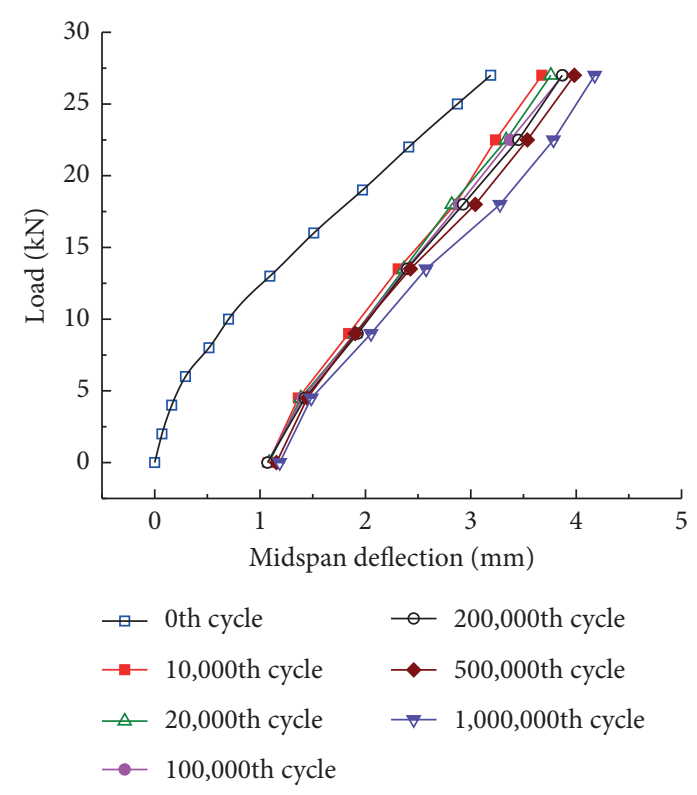

(b)

Figure 6: Load versus midspan deflection. (a) Specimen B-3. (b) Specimen JB-3.

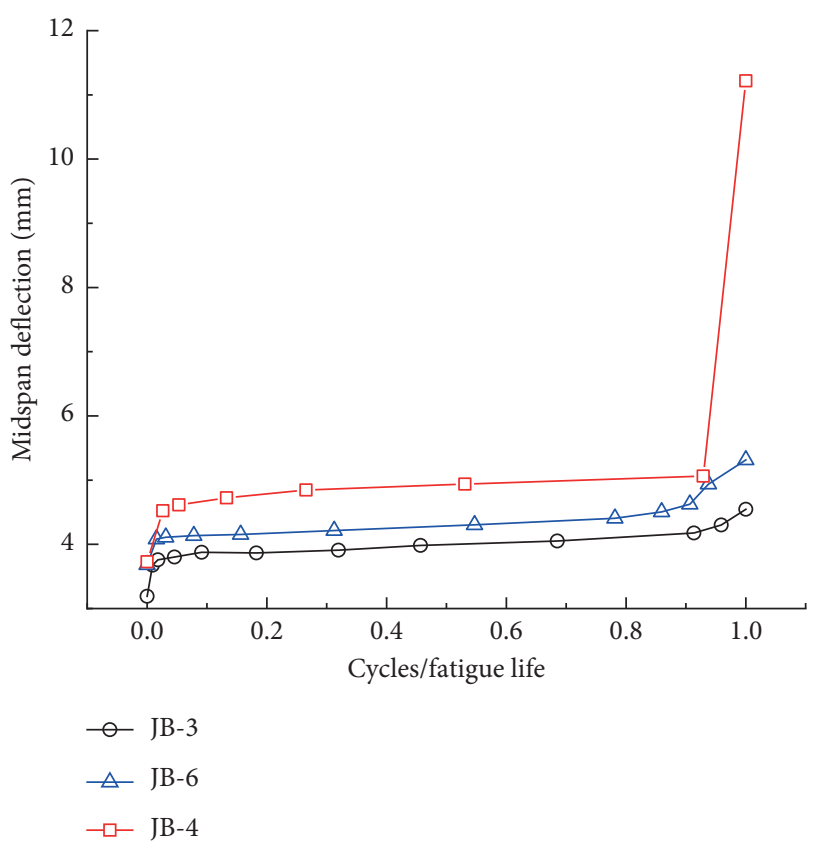

Figure 7: Midspan deflection curve under upper load.

3.2.3. Strain Evolvement. CFRP plates were combined with fiber grating to form CFRP-OFBG intelligent composite plates, which provided CFRP board intelligent characteristics and met long-term monitoring needs of structural health [21].

Data was measured by the FBG sensor was FBG's center wavelength. To obtain stress and strain values, calculation transformation was required. Strain was calculated using the following equation:

$$
\varepsilon=\frac{\left(\lambda_{i}-\alpha_{T} \cdot \Delta T\right)-\lambda_{0}}{k},
$$

where $\lambda_{i}$ is the wavelength (nm) of fiber grating in real time, $\lambda_{0}$ is the initial wavelength (nm) of fiber gratings, $\Delta T$ is the temperature change $\left({ }^{\circ} \mathrm{C}\right), \alpha_{T}=0.01 \mathrm{~nm} /{ }^{\circ} \mathrm{C}$ is the fiber grating temperature correction coefficient, and $k=0.0012 \mathrm{~nm} / \mu \varepsilon$ is the fiber grating strain coefficient term.

In specimen JB-6, although the strain values of CFRPOFBG were significantly higher than that of steel, their development trends were similar to the increase of cycle number. Figure 8(a) shows that CFRP-OFBG plates underwent rapid-stable-unstable growth with a similar trend as midspan deflection development.

The strain curve of specimen JB-5 is shown in Figure 8(b). It was observed that the overall development of CFRP strain was similar to that of specimen JB-3 except for the rapid decline at early stage. The observed rapid declining mutation could be due to CFRP-OFBG debonding under higher loads.

To investigate the effect of CFRP-OFBG on strain, Figure $8(\mathrm{c})$ presents strain evolution of unreinforced specimen B-3 and reinforced specimen JB-3. Under the same load cycle conditions, the strain value of the reinforced beam after 10,000 cycles was much smaller than that of the unreinforced beam. This was attributed to the contribution of CFRP-OFBG plate which participates in force after reinforcing the test beam, which shared the stress that tensile steel bar original bears. Therefore, the strain value of tensile reinforcement in reinforced beams was significantly reduced, as shown in Figure 8(c). In order to restore the original strain value, the number of load cycles on reinforced beam was significantly higher than that of unreinforced beam, which indicated that CFRP-OFBG reinforcement improved the fatigue life of test beam.

Under fatigue load, internal damage was gradually accumulated by increasing cycle number and external performance was the increase of test specimen deflection and 


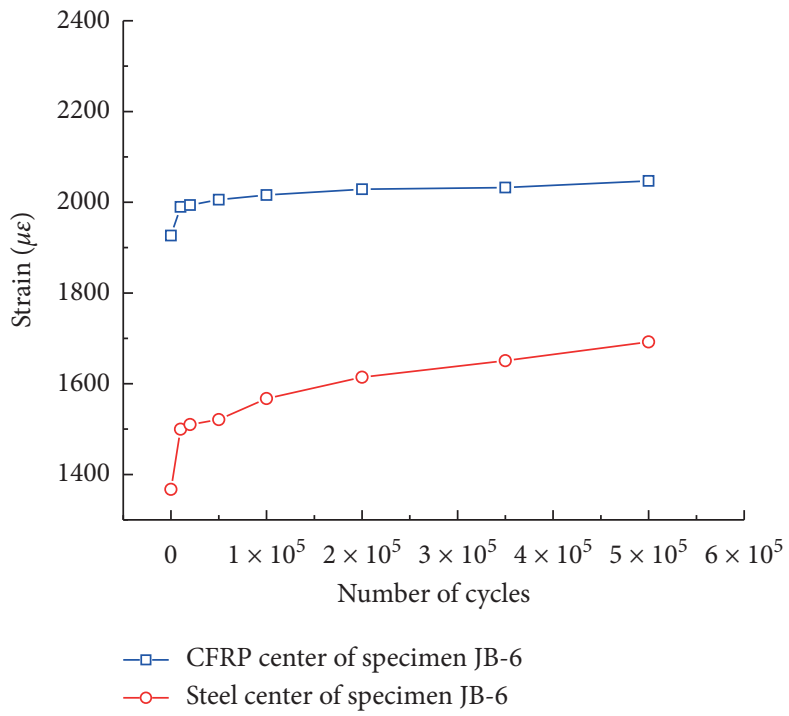

(a)

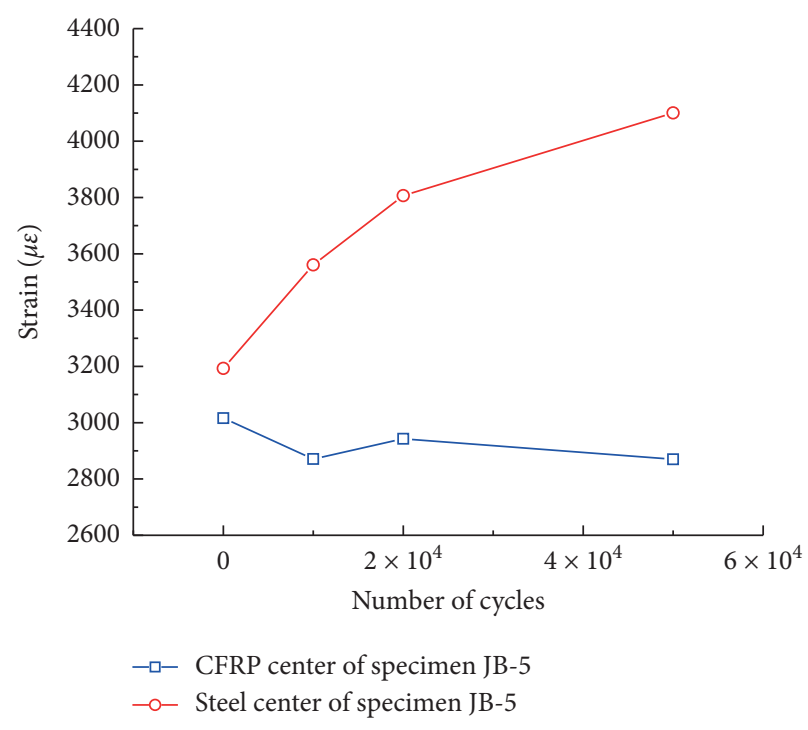

(b)

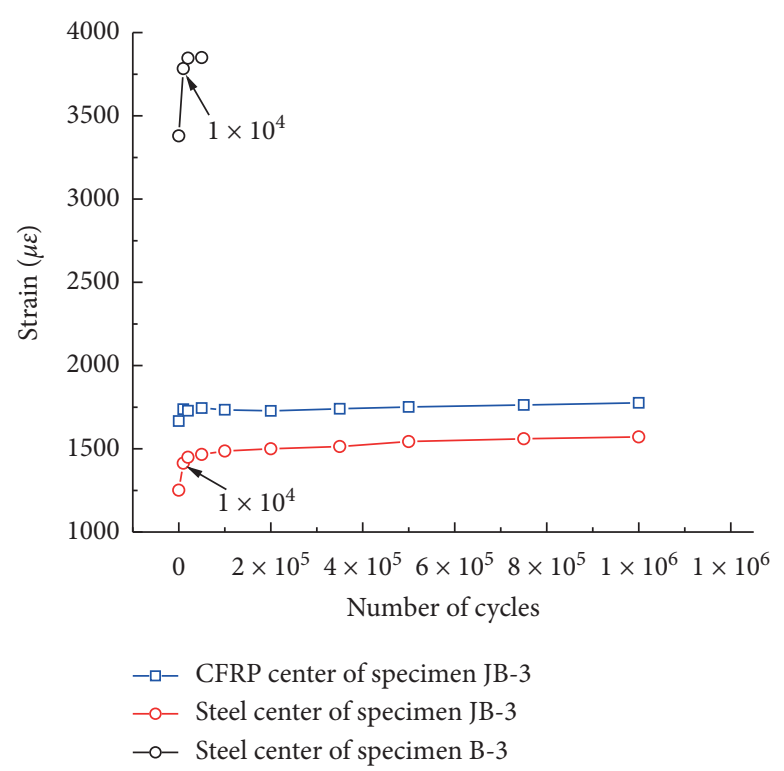

(c)

FIgURe 8: Curves of CFRP strain and steel versus the number of cycles. (a) $P_{\max }=30 \mathrm{kN}$. (b) $P_{\max }=39 \mathrm{kN}$. (c) $P_{\max }=27 \mathrm{kN}$.

crack development and extension. Figure 9 shows the variation of compressive strain value at the edge of compression zone concrete in reinforced beam at $P_{\max }$ with load cycle number. It was seen from the figure that concrete damage was irreparable. After the concrete was cracked, it entered a plastic working state. As load cycle number and stress level was increased, damage speed of concrete increasingly accelerated.

3.2.4. Fatigue Life. The failure modes of specimens matched the expected fatigue failure modes, which included main steel fatigued fracture. The corresponding cycle number at this moment was taken as the fatigue life of reinforced beams, rather than the number of cycles corresponding to CFRP-OFBG debonding. Figure 10 presents the relation of beam fatigue life and main steel stress amplitude on logarithmic, including some experimental data of other CFRP reinforced beams [23-26].

As shown in Figure 10, a linear relationship was observed between these two parameters. Linear regression equations of experimental data presented in Figure 10 were obtained according to least square method as

$$
\begin{gathered}
\log (N)=21.44011-6.45259 \log (\Delta \sigma), \quad R^{2}=1 \text { (Barnes), } \\
\log (N)=22.98749-6.97301 \log (\Delta \sigma), \quad R^{2}=0.93309
\end{gathered}
$$

(Papakonstantinou), 


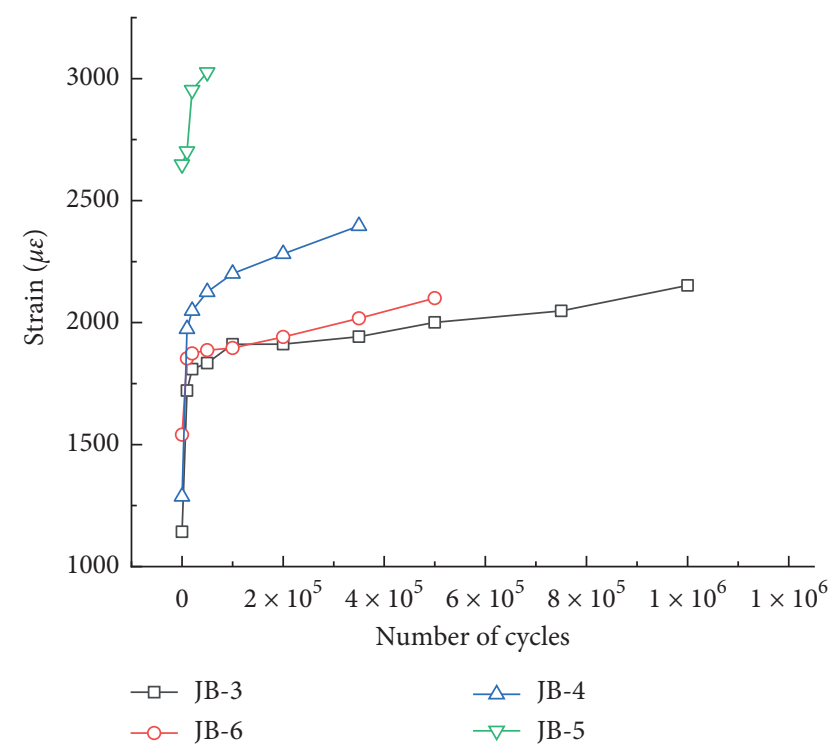

FIGURE 9: Strain values of compression zone concrete with cycle number.

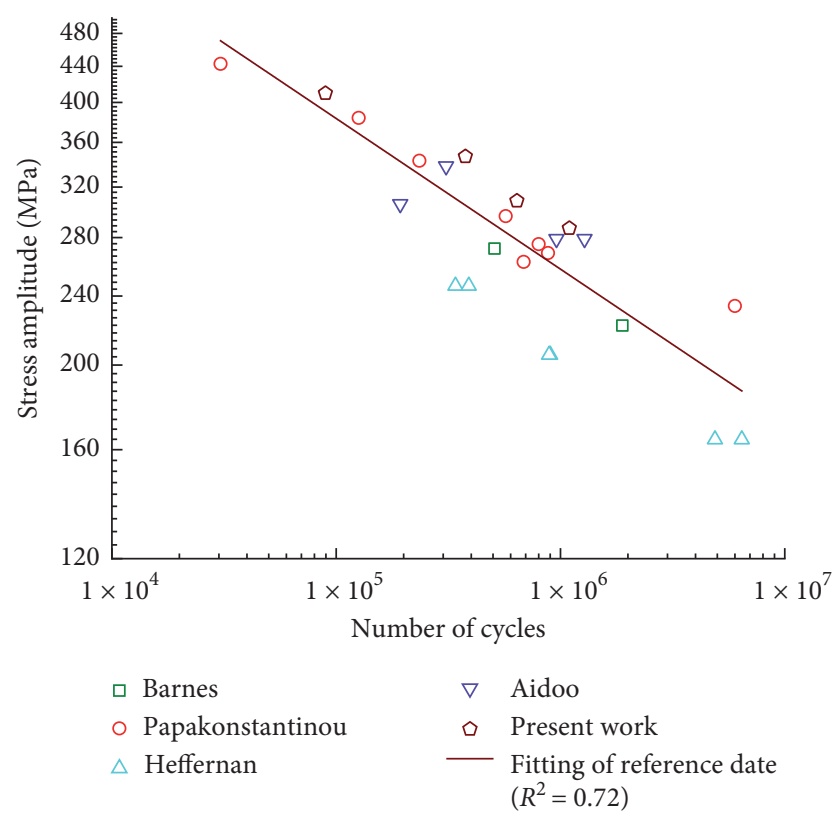

FIgURE 10: Steel stress amplitude versus cycle number in logarithmic scale.

$$
\log (N)=21.77323-6.79953 \log (\Delta \sigma), \quad R^{2}=0.97533
$$

(Heffernan),

$$
\log (N)=24.59083-7.62161 \log (\Delta \sigma), \quad R^{2}=0.59843
$$

$$
\log (N)=22.92105-6.86223 \log (\Delta \sigma), \quad R^{2}=0.98408
$$

(Present work),
For the overall statistical analysis of the above data, the following equation was applied:

$$
\log (N)=16.03936-4.19333 \log (\Delta \sigma), \quad R^{2}=0.72417 .
$$

Because the steel bar test environment was different, the fatigue analysis had a certain influence, so the presented regression equation was used only as engineering design reference.

Traditionally, if cycle number exceeds 2,000,000, beam fatigue life is assumed as being infinite. Therefore, defining fatigue strength as steel stress amplitude seems to be reasonable and the fatigue life is 2,000,000 cycles at the stress amplitude. So, set $N_{f}$ at 2,000,000 cycles in (7). Reinforced beam fatigue strength was calculated to be $247 \mathrm{MPa}$. Table 2 lists the stress amplitudes of steel bars at 2,000,000 cycles obtained from the S-N curves of relevant research data.

According to the data presented in Table 2, after reinforcing with CFRP-OFBG, allowable amplitude of stress for steel bars was significantly increased compared to stress amplitude limit of steel in unreinforced specimens, indicating that CFRP-OFBG reinforcement significantly improved the fatigue life of specimen. This was due to the fact that CFRP-OFBG directly resisted tensile force and shared and reduced the main steel stress. Secondly, CFRP-OFBG effectively limited deformation development in specimens in later stages of fatigue life and therefore main steel stress did not change much throughout the life cycle improving its service life.

\section{Fatigue Life Prediction}

Here, a fatigue life prediction method has been proposed for residual flexural stiffness of beams reinforced with CFRPOFBG based on experimental findings. This method could quickly evaluate the damage of reinforcement members and whether the components reached ultimate fatigue life.

4.1. Flat Section Hypothesis. Figure 11 shows strain distribution along the section height of the reinforced beams at different cycles. It can be seen that the specimens JB-3, JB-4, and JB-6 conformed to the flat section assumption during fatigue cyclic loading process. However, CFRP-OFBG plate strain at the bottom of specimen JB-5 was not linear as concrete and steel strain, and its value was significantly lower than that of main steel. This was inconsistent with actual situation, probably because concrete was exposed to excessive stress and damage which caused OFRP-OFBG plate to be peeled off to a certain extent disturbing its proper performance. However, regarding overall trend, when stress level was constant, the section strain of component was in accordance with flat section hypothesis throughout the fatigue life cycle. The following theoretical analysis was also based on this assumption.

4.2. Bending Stiffness Attenuation Law. It was seen from the experimental analysis that the section strain of reinforced 
TABle 2: The contrast of the S-N curves in differences.

\begin{tabular}{lcccccc}
\hline$(2)$ & $(3)$ & $(4)$ & $(5)$ & $(6)$ & ACI (1992) \\
\hline $221.9 \mathrm{MPa}$ & $247.2 \mathrm{MPa}$ & $188.6 \mathrm{MPa}$ & $251.0 \mathrm{MPa}$ & $264.2 \mathrm{MPa}$ & $210.1 \mathrm{MPa}$ & $121.4 \mathrm{MPa}$ \\
\hline
\end{tabular}
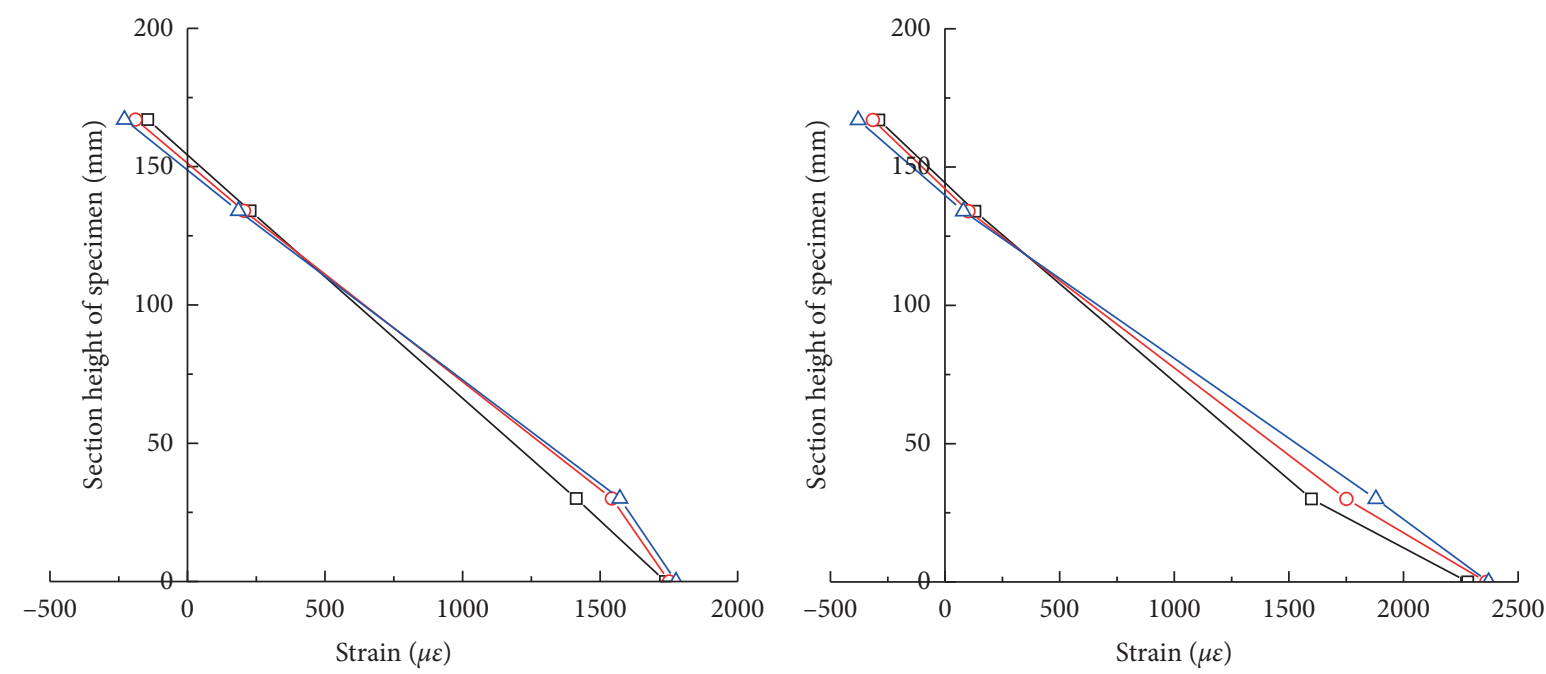

$\rightarrow-10,000$ th cycle
$\multimap-500,000$ th cycle
$-\triangle \quad 1000,000$ th cycle

(a)

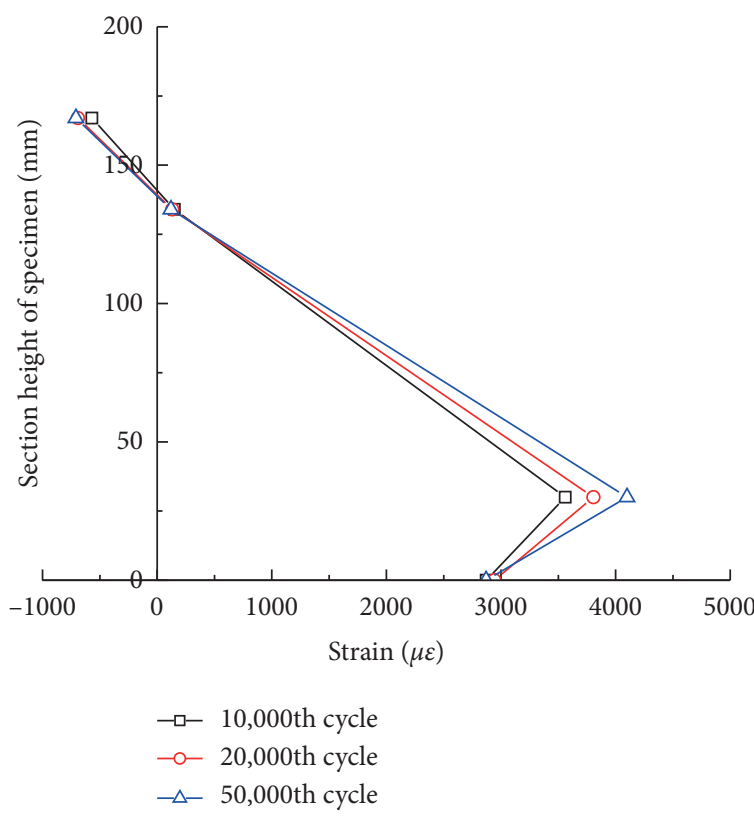

(c) $-\square-10,000$ th cycle

- 100,000 th cycle

$-\triangle$ 350,000th cycle

(b)

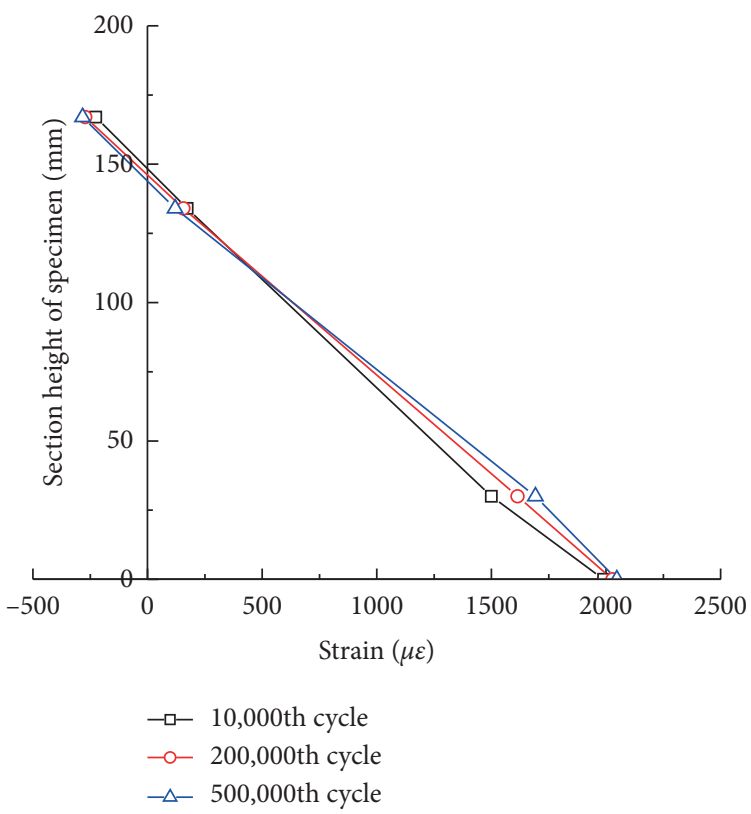

(d)

FIGURE 11: Strain distribution of specimens along the height of control section. (a) Specimen JB-3. (b) Specimen JB-4. (c) Specimen JB-5. (d) Specimen JB-6.

specimens in normal use stage was consistent with flat section assumption throughout fatigue life cycles. Therefore, average curvature method was used to calculate the stiffness of reinforced specimens.
Sectional mean curvature $\phi_{n}$ was stated as

$$
\phi_{n}=\frac{1}{\rho_{n}}=\frac{\left|\varepsilon_{c n}\right|+\left|\varepsilon_{c f n}\right|}{h_{f}} .
$$


Calculation of bending stiffness during fatigue tests on reinforced specimens was performed using curvature method $B_{n}$ as

$$
B_{n}=\frac{M}{\phi_{n}}=\frac{M \times h_{f}}{\left|\varepsilon_{c n}\right|+\left|\varepsilon_{c f n}\right|},
$$

where $M$ is the value of bending moment acting on specimen, $\varepsilon_{c n}$ is the average compressive strain of corresponding concrete compression zone after $n$ cycles, $\varepsilon_{c f n}$ is the average tensile strain of CFRP-OFBG plate after $n$ cycles, $\phi_{n}$ is corresponding section average curvature after $n$ cycles, $B_{n}$ is the bending stiffness of corresponding reinforced beam after $n$ cycles, and $h_{f}$ reinforce the entire section height of the beam.

According to (8) and (9), the residual bending stiffness of corresponding reinforcement beam section was calculated when load was applied to upper limit of fatigue at different cycles. Figure 12 shows the decay of flexural stiffness of reinforced specimens during the entire fatigue cycle.

It was seen from Figure 12 that the cross-sectional bending stiffness $B_{n}$ of reinforced beams was decreased with the increase of cycle number and a three-stage decay trend was obtained during the whole fatigue process. In the first stage of fatigue damage, initial rapid decay phase $(0 \% \sim 5 \%)$, the bending stiffness of specimens quickly decayed. The bending stiffness of each specimen was reduced to about $80 \%$ of the initial value at the end of this stage. In the second stage, bending stiffness decayed into a relatively stable phase, slow decay phase (5\% 90\%), accounting for $85 \%$ of the whole fatigue life. Good linear relationships were observed between $B_{n}$ and $N / N_{G}$ for all specimens, except for JB-5. In the third stage of fatigue damage, rapid decay stage $(90 \%$ $100 \%)$, bending stiffness was extremely attenuated until the specimen was destroyed.

4.3. Accumulative Damage Model. Test results revealed obvious fatigue damage of reinforced beams by the reduction of bending stiffness. In addition, since stiffness is an absolute value and its value for different specimens may be greatly different, relative damage values could be uniformly used when measuring specimen damage at different cycles. Consequently, developing a model for fatigue cumulative damage on the basis of flexural stiffness of CFRP-OFBG reinforced beams was reasonable. The fatigue damage value $D_{N}$ of reinforced beams was stated as

$$
D_{N}=1-\frac{B_{N}}{B_{0}}
$$

where $D_{N}$ is the cumulative damage value for stiffness, ranging from 0 to $1, B_{0}$ is the initial bending stiffness when there is no damage, and $B_{N}$ is the residual bending stiffness of the specimens after $N$ cycles.

Figure 13 presents the relationship between $N / N_{G}$ and $D_{N}$.

The results obtained from Figures 12 and 13 are given in Table 3, where the destructive stiffness ratio was the ratio of

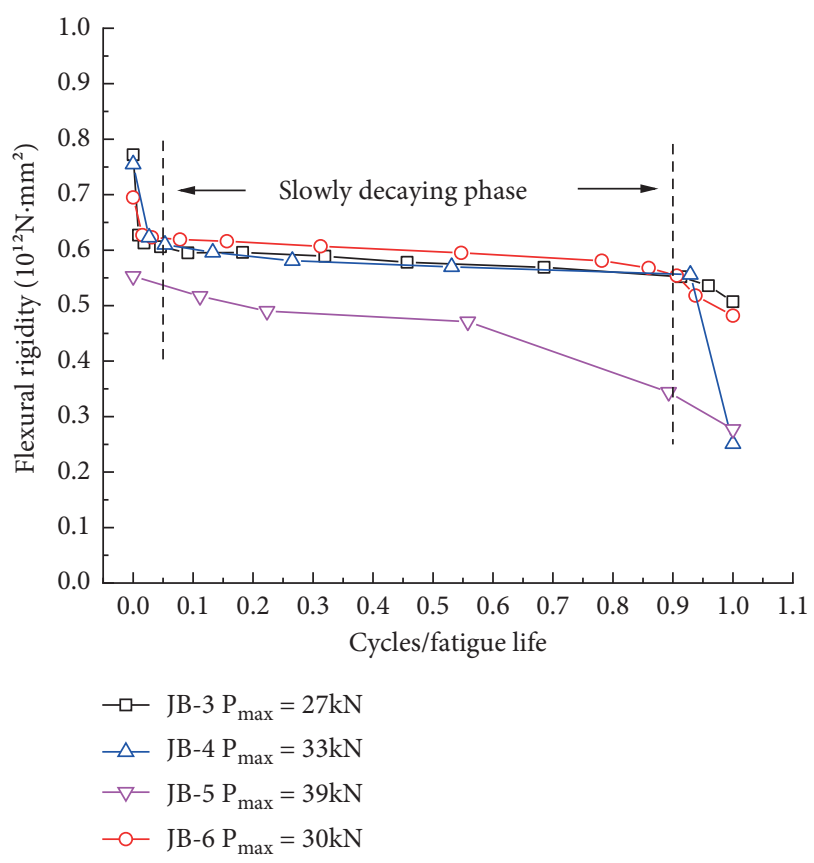

FIGURE 12: Flexural stiffness attenuation curve of reinforced beam section.

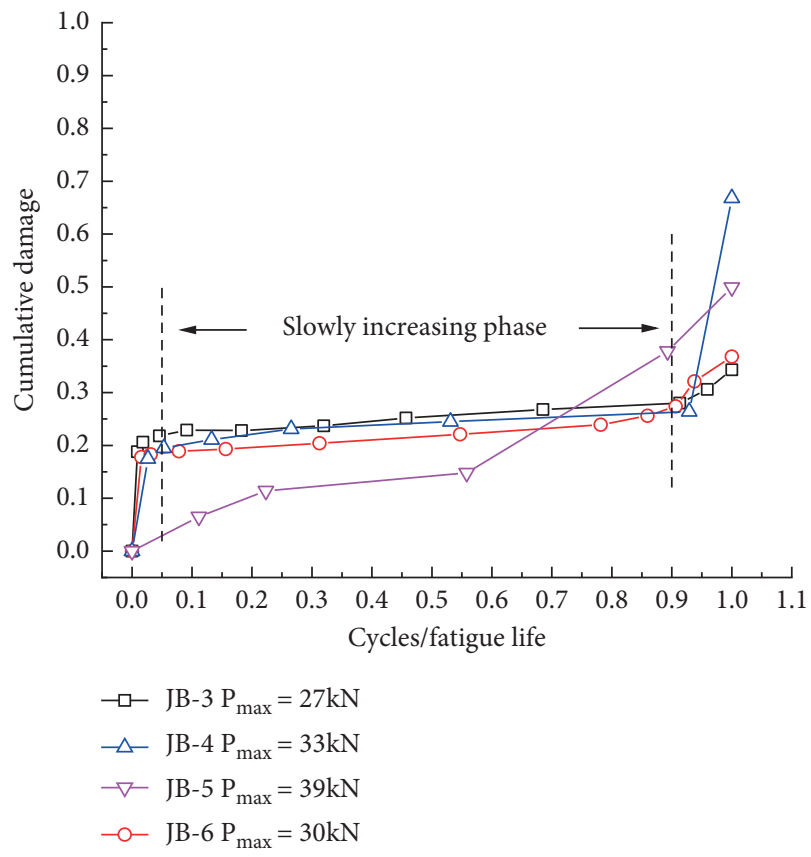

FIgURE 13: Cumulative damage curve of reinforced beam section.

residual stiffness $B_{f}$ of the beam near failure to initial stiffness $B_{0}$.

The reason for low bending stiffness of JB-5 was mainly that the CFRP of end portion started to debond at cycle numbers of above 50,000. The CFRP of tension zone had lower contribution to force in the subsequent 39,600 cycles, which resulted in great reduction in bending stiffness. By analyzing the test data obtained from reinforced specimens, the average values of $B_{f} / B_{0}$ and $D_{N}$ were found to be 0.728 
TABLE 3: Analysis results of bending stiffness of reinforced beams in fatigue tests.

\begin{tabular}{lcccc}
\hline Specimens & Initial stiffness $B_{0}$ & Destructive stiffness $B_{f}$ & Destructive stiffness ratio $B_{f} / B_{0}$ & Cumulative damage value $D_{N}$ \\
\hline JB-3 & 0.772 & 0.558 & 0.721 & 0.279 \\
JB-4 & 0.755 & 0.559 & 0.737 & 0.263 \\
JB-5 & 0.553 & 0.344 & 0.622 & 0.378 \\
JB-6 & 0.763 & 0.554 & 0.726 & 0.274 \\
Statistics & - & - & 0.728 & 0.272 \\
\hline
\end{tabular}

${ }^{\mathrm{a}} \mathrm{JB}-5$ did not conform to the three-stage development law and was not included in statistical value.

and 0.272 . This meant that regardless of initial stiffness of reinforced beams, as long as residual bending stiffness was reduced to $72.8 \%$ of initial stiffness, specimens underwent fatigue damage and their service life was ended.

According to the above changing rules, a three-stage linear stiffness damage model corresponding to the law of damage development had been developed in this paper:

$$
D_{N}= \begin{cases}k_{1} \frac{N}{N_{G}}, & 1 \leq N \leq 0.05 N_{G}, \\ D_{1}+k_{2}\left(\frac{N-0.05 N_{G}}{N_{G}}\right), & 0.05 N_{G} \leq N \leq 0.9 N_{G}, \\ D_{2}+k_{3}\left(\frac{N-0.9 N_{G}}{N_{G}}\right), & 0.9 N_{G} \leq N \leq N_{G} .\end{cases}
$$

where $k_{1}, k_{2}, k_{3}$ are the damage growth rates in the first, second, and third deformation stages and $D_{1}, D_{2}$ are the damage magnitude at the end of the first and the second phases, respectively.

Table 4 shows the damage development coefficients of each specimen. Since JB-5 did not conform to the three-stage development law, its data were not considered in the analysis of the damage development presented in the table.

Specimens began to break at the third stage, which made it impossible to obtain stable data. The value of $k_{3}$ was more discrete and was not included in the statistical analysis showed in Table 4 . In the third stage, fatigue lives were small. Generally, bending stiffness at the end of the second stage is taken as the fatigue failure stiffness of specimens and the corresponding damage model considers only the first and second stages:

$$
D_{N}= \begin{cases}k_{1} \frac{N}{N_{G}}, & 1 \leq N \leq 0.05 N_{G} \\ D_{1}+k_{2}\left(\frac{N-0.05 N_{G}}{N_{G}}\right), & 0.05 N_{G} \leq N \leq 0.9 N_{G} .\end{cases}
$$

Accumulative damage model was considered for all stages which could be used to accumulate damage values $D_{N}=1$ as the basis for determining the failure of reinforced beams. Regardless of the model applied in the third stage, $D_{N}=0.272$ was assumed as the basis for determining the failure of reinforced beams. Considering that the test
TABLE 4: Statistical results of relative parameters in damage curve.

\begin{tabular}{lccccc}
\hline Specimens & $k_{1}$ & $k_{2}$ & $k_{3}$ & $D_{1}$ & $D_{2}$ \\
\hline JB-3 & 4.36 & 0.07040 & - & 0.218 & 0.279 \\
JB-4 & 3.90 & 0.07315 & - & 0.195 & 0.263 \\
JB-6 & 3.76 & 0.08072 & - & 0.188 & 0.274 \\
Statistics & - & 0.07476 & - & 0.200 & 0.272 \\
\hline
\end{tabular}

specimens were generally in the second stage of damage development under normal conditions, the fatigue lives of reinforcing beams were predicted using

$$
D_{N}=0.05 k_{1}+k_{2}\left(\frac{N}{N_{G}}-0.05\right),
$$

where $k_{1}$ recommended $N / N_{G}$ linear regression from data from 0 to 0.05 to determine the value of $k_{1}$ and $D_{1}$ was considered to be 0.200 in this work. $k_{2}$ is the linear relationship, and its value was taken as 0.07476 . Equation (13) could be rewritten as

$$
D_{N}=0.2+0.07476\left(\frac{N}{N_{G}}-0.05\right) \text {. }
$$

4.4. Fatigue Life Prediction Results. Taking specimen JB-3 as an example, the predicted cycles of the second stage (5\% $90 \%)$ and corresponding test values of section bending stiffness were substituted into (14) to predict the fatigue life $N_{P}$ of specimen. The results are summarized in Table 5.

The details of the results in Table 5 are available.

Using (8) and (9), the section bending stiffness of reinforced beams could be quickly calculated under different cycles and ratio of $N / N_{G}$ could be obtained. When $N / N_{G}=1$, accumulative damage value reached 0.272 , which meant that the reinforced beam was close to $90 \%$ of its ultimate fatigue life and it was about to enter the stage of instability and rapid decay. $N_{P 1}$ indicates fatigue life at the end of the second stage. In order to get the total fatigue life $N_{P 2}, N_{P 1}$ needed to be divided by $90 \%$ and the error was around $10 \%$. This was mainly due to the fact that the number of test specimens was low and the obtained data were highly dispersed. In addition, limited by test machine, specimen sizes were too small, intensifying the effects of accidental factors.

By comparing theoretical calculation data with experimental findings, good complying was obtained. Bending stiffness changes of reinforced beam sections were analysed by real-time monitoring and date acquisition of intelligent CFRP-OFBG plate in actual engineering projects. With this 
TABLE 5: Comparison between prediction values and test results for fatigue life based on the flexural rigidity of reinforced beam sections.

\begin{tabular}{lccccc}
\hline Cycles & JB-3 $B_{n}$ & $D_{N}$ & $\begin{array}{c}\text { Fatigue life } N_{P 1} \\
(10,000 \text { cycles })\end{array}$ & $\begin{array}{c}\text { Fatigue life } N_{P 2} \\
(10,000 \text { cycles })\end{array}$ & $\begin{array}{c}\text { Fatigue life } N_{G} \\
(10,000 \text { cycles })\end{array}$ \\
\hline 200,000 & 0.596 & 0.228 & 47.11 & 52.34 & \\
350,000 & 0.589 & 0.237 & 64.23 & 71.37 & 109.48 \\
500,000 & 0.578 & 0.252 & 67.06 & 74.52 & 10.33 \\
750,000 & 0.565 & 0.268 & 78.16 & 86.84 & \\
$1,000,000$ & 0.556 & 0.280 & 89.28 & 99.20 & \\
\hline
\end{tabular}

method, specimen damages and ultimate fatigue lives of the component were quickly evaluated.

\section{Conclusion}

The fatigue performance of beams externally reinforced with intelligent CFRP-OFBG plates was experimental investigated in this work. Static tests showed that the bearing capacity of beams with reinforced with CFRPOFBG was significantly higher than unreinforced specimens. Fatigue test results showed that the fatigue failure of reinforced beams was caused by CFRP-OFBG debonding after the main reinforcement fracture. Tensile steel stress amplitude plays a key role in the fatigue life of reinforced beams and fatigue strength was $247 \mathrm{MPa}$. Compared with unreinforced beams in this study, CFRP-OFBG reinforcement further decreased the fatigue damages and steel stress of the tensile reinforcement, thereby improving beam fatigue life. Fatigue tests showed that fatigue damage was a three-stage process including initiation, stable expansion growth, and unstable expansion growth phases. Stable propagation phase composed more than $85 \%$ of the whole fatigue life.

Besides, based on the real-time monitoring data of intelligent CFRP-OFBG plate, this paper has introduced the concepts of residual stiffness and accumulative damage. A fatigue accumulative damage model was developed for the prediction of reinforced beam fatigue life. Compared with the experimental values, the effectiveness of the established method in the prediction of beam fatigue life was proven and it was shown that the model could be used in designing actual fatigue components as a preliminary reference to estimate fatigue life.

\section{Data Availability}

The data used to support the findings of this study are available from the corresponding author upon request.

\section{Conflicts of Interest}

The authors declare that there are no conflicts of interest regarding the publication of this paper.

\section{Acknowledgments}

The authors acknowledge the financial support provided by the National Natural Science Found (No. 51568008).

\section{References}

[1] Y. Su, C. Wu, and M. C. Griffth, "Modelling of the bond-slip behavior in FRP reinforced masonry," Construction and Building Materials, vol. 25, no. 1, pp. 328-334, 2011.

[2] American concrete institute (ACI), Guide for the Design and Construction of Externally Bonded FRP Systems for Strengthening Concrete Structures, vol. 440, ACI Committee, Farmington Hills, MI, USA, 2012.

[3] X. S. Xu and T. C. Wang, "Experimental research on mechanical property of high-performance fiber reinforced plastics (FRP)," in Proceedings of International Conference on Transportation Engineering (ICTE), American Society of Civil Engineers, Reston, VA, USA, pp. 2223-2228, July 2007.

[4] Z. Y. Shao, "Discussion on modern bridge reinforcement technology," Construction Technology, vol. 45, no. supplement, pp. 295-299, 2016.

[5] P. C. Paris and F. Erdogan, "A critical analysis of crack propagation laws," Journal of Basic Engineering, vol. 85, no. 5, pp. 528-534, 1963.

[6] P. D. Hobson and M. W. Brown, "The behavior of short fatigue cracks," Fatigue Engineering Materials and Structures, no. 5, pp. 323-327, 1982.

[7] C. S. Wang, J. Zhou, Q. Y. Wu et al., "Fatigue life and safety assessment of existing concrete bridges," China Journal of Highway and Transport, vol. 25, no. 6, pp. 101-107, 2012.

[8] J. Sun, Z. Ding, and Q. Huang, "Corrosion fatigue life prediction for steel bar in concrete based on fatigue crack propagation and equivalent initial flaw size," Construction and Building Materials, vol. 195, pp. 208-217, 2019.

[9] K. Kihyon, M. F. Dan, and S. Mohamed, "Probabilistic fatigue life estimation of steel bridges by using a bilinear S-N approach," Journal of Bridge Engineering, vol. 17, no. 1, pp. 58-70, 2012.

[10] L. D'Angelo and A. Nussbaumer, "Reliability based fatigue assessment of existing motorway bridge," Structural Safety, vol. 57, pp. 35-42, 2015.

[11] L. N. Deng and Z. H. Yu, Research on the Performance and Reinforcement Application of CFRP-OFBG Intelligent Carbon Fiberboard, Guangxi University of Science and Technology, Liuzhou, Guangxi, 2014.

[12] J. Leander and R. Karoumi, "Dynamics of thick bridge beams and its influence on fatigue life predictions," Journal of Constructional Steel Research, vol. 89, pp. 262-271, 2013.

[13] Z. Al-Azzawi, T. Stratford, M. Rotter, and L. Bisby, "FRP strengthening of web panels of steel plate girders against shear buckling. part-II: fatigue study and cyclic series of tests," Composite Structures, vol. 210, pp. 82-95, 2019.

[14] A. L. Kalamkarov, D. O. MacDonald, S. B. Fitzgerald et al., "Reliability assessment of pultruded FRP reinforcements with embedded fiber optic sensors," Composite Structures, vol. 50, no. 4, pp. 69-75, 2000. 
[15] Z. Zhou, J. P. Ou, and B. Wang, "Smart FRP-OFBG bars and their application in reinforced concrete beams," in Proceedings of the First International Conference on Structural Health Monitoring and Intelligent Structure, pp. 861-866, Institute of Physics Publishing, Tokyo, Japan, 2003.

[16] J. P. Ou, Z. Zhou, and B. Wang, "FRP-OFBG intelligent composite rib and its application in reinforced concrete beams," High Tech Communications, vol. 15, no. 4, pp. 23-28, 2006.

[17] P. Zhang, L. Liao, X. P. Yan et al., "Development of new FRPOFBG intelligent steel strand and its material properties," Concrete, vol. 2, pp. 87-89, 2010.

[18] P. Zhang, X. Zhong, L. N. Deng et al., "Full-process analysis method of unbonded partially prestressed concrete beams based on FPR-OFBG intelligent steel strands," Concrete, vol. 8, pp. 27-29, 2011.

[19] L. Liao, L. N. Deng, P. Zhang et al., "Fiber-grating fiber reinforced composite pultrusion continuous forming intelligent board," Chinese Utility Model Patent 201320745149, 2013.

[20] L. Liao and L. N. Deng, "Fiber-reinforced fiber reinforced composite pultrusion continuous forming intelligent board and its preparation method," Chinese invention patent application: 201310595487, 2013.

[21] L. N. Deng, J. Y. Liang, L. Liao et al., "Experimental study on flexural behavior of steel beams strengthened with prestressed carbon fiber sheets based on fiber Bragg grating," Journal of Guangxi University of Science and Technology, vol. 26, no. 2, pp. 73-77, 2015.

[22] J. H. Xie, P. Y. Huang, and Y. C. Guo, "Fatigue behavior of reinforced concrete beams strengthened with prestressed fiber reinforced polymer," Construction and Building Materials, vol. 27, no. 1, pp. 149-157, 2012.

[23] R. A. Barnes and G. C. Mays, "Fatigue performance of concrete beams strengthened with CFRP plates," Journal of Composites for Construction, vol. 3, no. 2, pp. 63-72, 1999.

[24] C. G. Papakonstantinou, M. F. Petrou, and K. A. Harries, "Fatigue behavior of RC beams strengthened with GFRP sheets," Journal of Composites for Construction, vol. 5, no. 4, pp. 246-253, 2001.

[25] J. Aidoo, K. A. Harries, and M. F. Petrou, "Fatigue behavior of carbon fiber reinforced polymer-strengthened reinforced concrete bridge girders," Journal of Composites for Construction, vol. 8, no. 6, pp. 501-509, 2004.

[26] P. J. Heffernan and M. A. Erki, "Fatigue behavior of reinforced concrete beams strengthened with carbon fiber reinforced plastic laminates," Journal of Composites for Construction, vol. 8, no. 2, pp. 132-140, 2004. 